\title{
Sistem Informasi Simpan Pinjam Multikoperasi Menggunakan Framework Laravel
}

\author{
${ }^{1}$ Gabriela Minang Sari, ${ }^{2}$ Tristiyanto \& ${ }^{3}$ Muhammad Iqbal \\ 1,2,3 Jurusan Ilmu Komputer FMIPA Universitas Lampung \\ Jalan Prof. Sumantri Brojonegoro No. 1 Bandar Lampung 35145 \\ ${ }^{1}$ gabriela.minang1058@ students.unila.ac.id, ${ }^{2}$ tristiyanto.1981@ fmipa.unila.ac.id, \\ ${ }^{3}$ muhammadiqbal@fmipa.unila.ac.id
}

\begin{abstract}
The initial purpose of saving and loan cooperative is giving a financial solution for the members only. As time goes by, nowadays cooperative can provide finance support for small enterprise and public society. Transactions which always increasing can cause trouble in data management. The price of the application that is relatively expensive can be a problem for cooperative which don't have any information system yet. Furthermore, user needs IT expert for maintaining and updating system. Saving and loan information system using SaaS model (Software as a Service) can be a solution to the problem. With the SaaS model users do not need to buy the app, just by subscribing with the application directly to use the application. Saving and loan multi cooperative information system developed for ease the saving and loan data management. Saving and loan multi cooperative information system developed with Extreme Programming method by using PHP languages, and Laravel Framework. The conclusion of this research is saving and loan multi cooperative information system is successfully built according to user needs, by displaying data transparently.
\end{abstract}

Keywords: Extreme Programming, Laravel framework, Information System

\section{PENDAHULUAN}

Koperasi simpan pinjam memiliki peranan dalam usaha pembentukan modal melalui tabungan-tabungan para anggota secara teratur dan terus-menerus untuk kemudian dipinjamkan kepada para anggota dengan cara mudah, murah, cepat dan tepat untuk tujuan produktif dan kesejahteraan [1]. Pengelolaan koperasi simpan pinjam pada dasarnya sama dengan koperasi lainnya, hanya saja terdapat sedikit perbedaan pada beberapa bagian teknis, dimana ruang lingkup kegiatan mencakup kegiatan menghimpun dan menyalurkan dana dalam bentuk penyaluran pinjaman terutama dari dan untuk anggota [2]. Tujuan awal dari koperasi simpan pinjam adalah memberikan solusi keuangan hanya untuk para anggota koperasi saja, namun seiring perkembangan kebutuhan yang ada di masyarakat, koperasi turut andil memberikan bantuan untuk kebutuhan usaha kecil dan menarik dana dari masyarakat umum [3]. Kegiatan penghimpunan dana pada koperasi simpan pinjam dilakukan secara terus menerus dan membuat data yang dikelola semakin meningkat. Pengelolaan data yang semakin besar tersebut membuat petugas kerap mengalami kesulitan karena sering terjadinya selisih jumlah transaksi dalam kegiatan simpan pinjam . Harga sistem yang relatif mahal, serta selisih jumlah transaksi dalam kegiatan simpan pinjam yang kerap terjadi membuat waktu terbuang serta dalam penyusunan laporan sering terjadi kesalahan dalam pengisian data.

Salah satu pemanfaatan internet sebagai Software as a Service (SaaS) dapat menjadi solusi dari masalah tersebut. SaaS dapat digunakan sebagai cara baru dalam pembiayaan dan pemakaian sumber daya teknologi informasi [4]. Implementasi SaaS tidak membutuhkan biaya yang mahal dan tidak memerlukan infrastruktur tambahan seperti hardware [5]. SaaS merupakan suatu model 
penyampaian aplikasi perangkat lunak dimana pengguna hanya perlu terhubung internet guna menggunakan aplikasi tersebut [6] tanpa membeli lisensi [7] karena lisensi akan diberikan setelah berlangganan [8] serta tanpa perlu memikirkan perawatan sistem karena penyedia yang melakukan perawatan sistem. Sistem Informasi Simpan Pinjam Multikoperasi dengan model SaaS dapat menjadi solusi dari masalah di atas. Pengembangan menggunakan model SaaS memungkinkan pengelola koperasi untuk menggunakan sistem tanpa perlu mengkhawatirkan mahalnya harga sistem. Selain itu, SaaS juga dapat mengurangi kesalahan dalam pengelolaan data simpan pinjam, dengan demikian resiko human error dapat dikurangi.

\section{METODE PENELITIAN 2.1 Tahapan Penelitian}

Tahapan penelitian dilakukan dengan beberapa langkah yaitu pengumpulan data, amalisis masalah, pengembangan sistem dan penulisan laporan. Diagram alir tahapan penelitian dapat dilihat pada gambar 1.

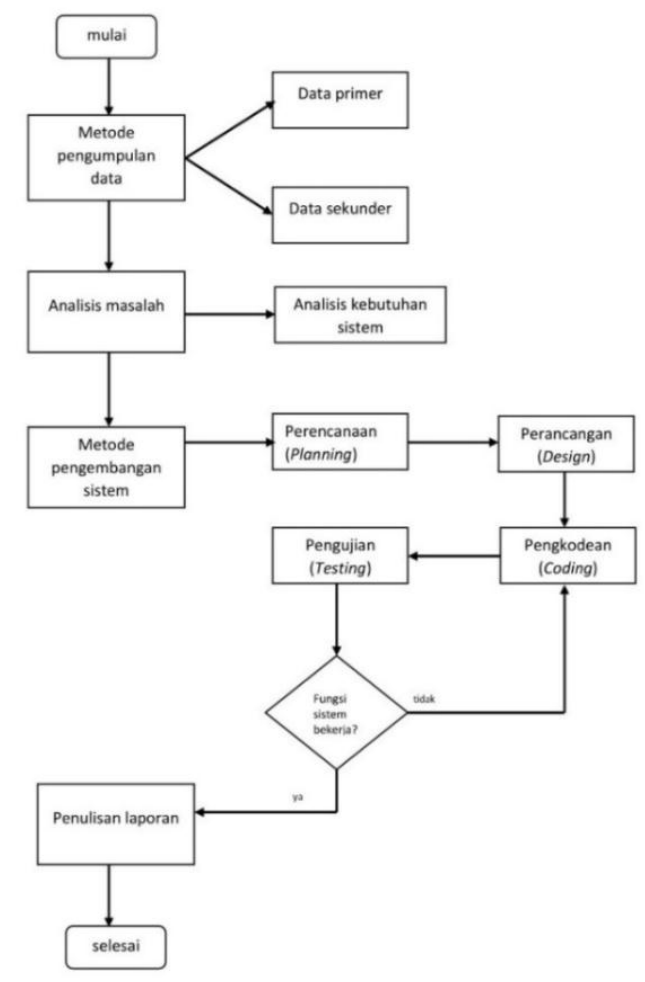

Gambar 1 tahapan penelitian

\subsection{Metode Pengembangan Sistem}

Metode pengembangan yang digunakan dalam penelitian ini adalah metode Extreme Programming. Tahapan yang dilakukan pada metode Extreme Programming ditunjukkan pada gambar 2. 
Vol 7 No. 2 , 2019

C2019 Ilmu Komputer Unila Publishing Network all rights reserved

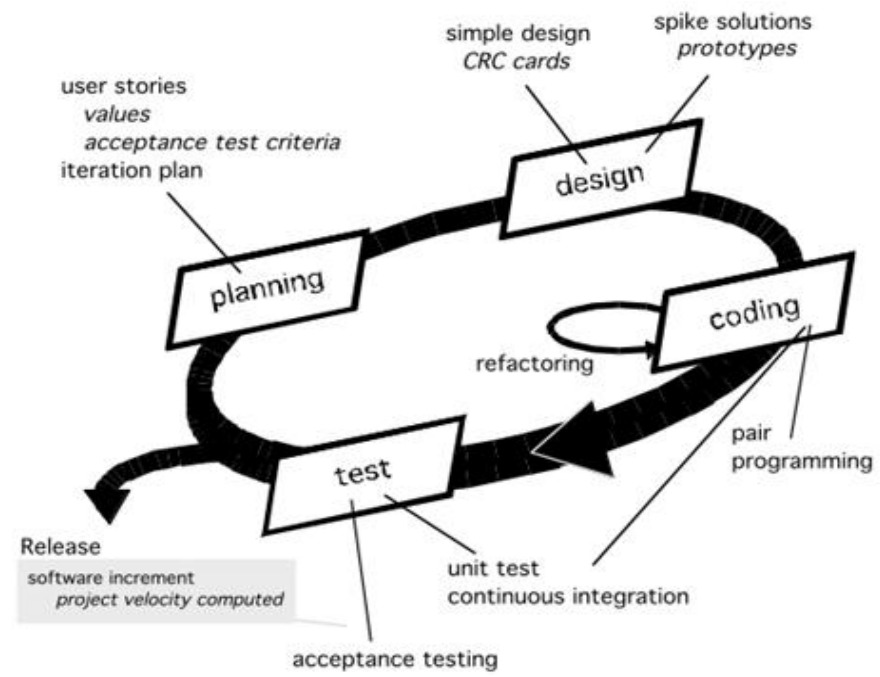

Gambar 2 tahapan extreme programming [9].

Metode pengembangan sistem pada penelitian ini menggunakan metode Extreme Programming. Adapun tahap yang dilakukan yaitu :

\section{A. Tahap Perencanaan (Planning)}

Tahap perencanaan meliputi pendalaman mengenai proses bisnis dan perencanaan sistem. Perencanaan sistem meliputi pembuatan Unified Modelling Language yang ditunjukkan pada gambar 3.

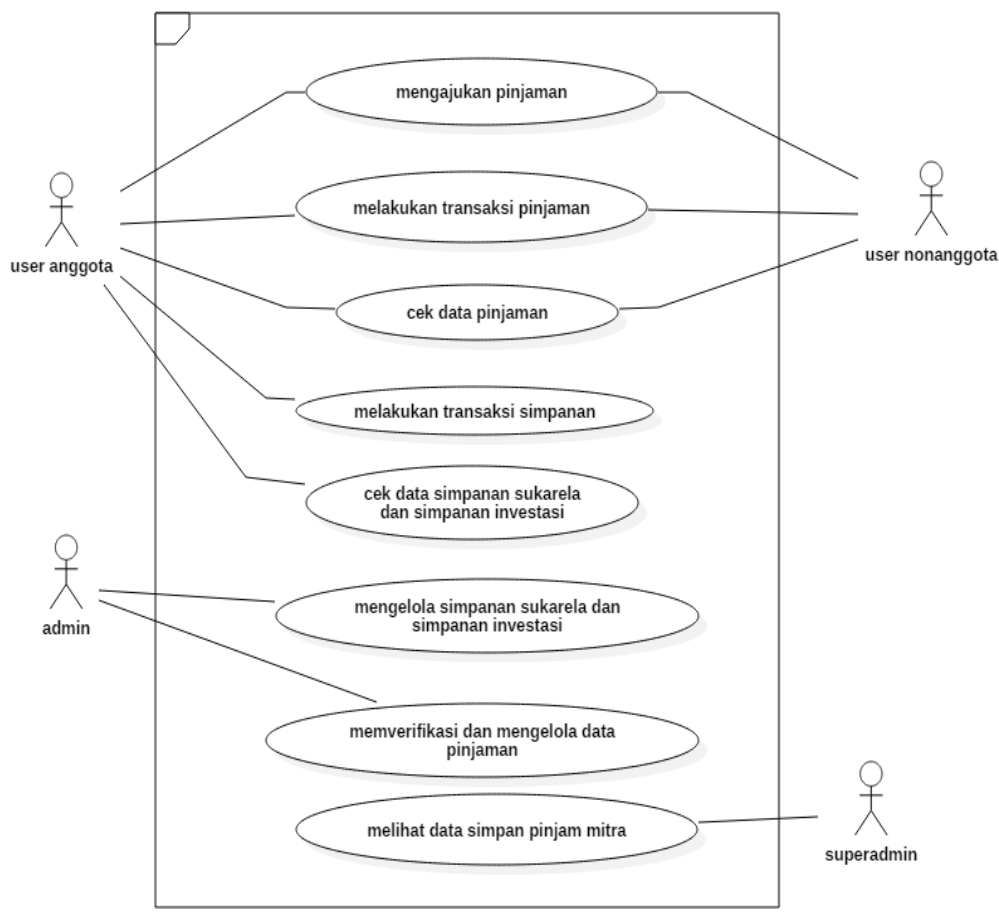

Gambar 3 usecase diagram sistem informasi simpan pinjam multikoperasi 
Pada gambar 3 terdapat empat level user yang berbeda. User tersebut dapat melakukan seperti berikut:

- Super Admin

Super Admin adalah pengembang dari SI Koperasi. Super Admin dapat melihat data yang berupa dari seluruh mitra yang menggunakan SI Koperasi tanpa dapat mengubahnya.

- Admin

Admin merupakan pengelola dari salah satu mitra koperasi. Admin dapat melakukan hal - hal yang berkaitan dengan pengelolaan simpan pinjam. Admin mengelola data anggota, data keuangan simpan pinjam serta memverifikasi pengajuan pinjaman.

- Anggota

Anggota dapat mengajukan pinjaman maupun menabung serta dapat melihat data milik anggota tersebut di tampilan yang tertera pada akun milik anggota.

- Nonanggota

Non anggota dapat melakukan registrasi untuk agar selanjutnya dapat mengajukan pinjaman. Setelah mendapat pinjaman non anggota dapat melihat data pinjaman milik non anggota tersebut.

\section{B. Tahap Perancangan (Design)}

Tahap ini dilakukan dengan merancang tampilan antarmuka (design interface). Perancangan antarmuka merupakan proses penggambaran bagaimana sebuah tampilan (interface) sistem dibentuk. Design interface Sistem Informasi Simpan Pinjam Multikoperasi menggunakan Framework Laravel dibuat dengan menggunakan tools Balsamiq Mockup tertera pada gambar berikut.

1. Design Interface User Anggota Checking Data Simpanan Sukarela

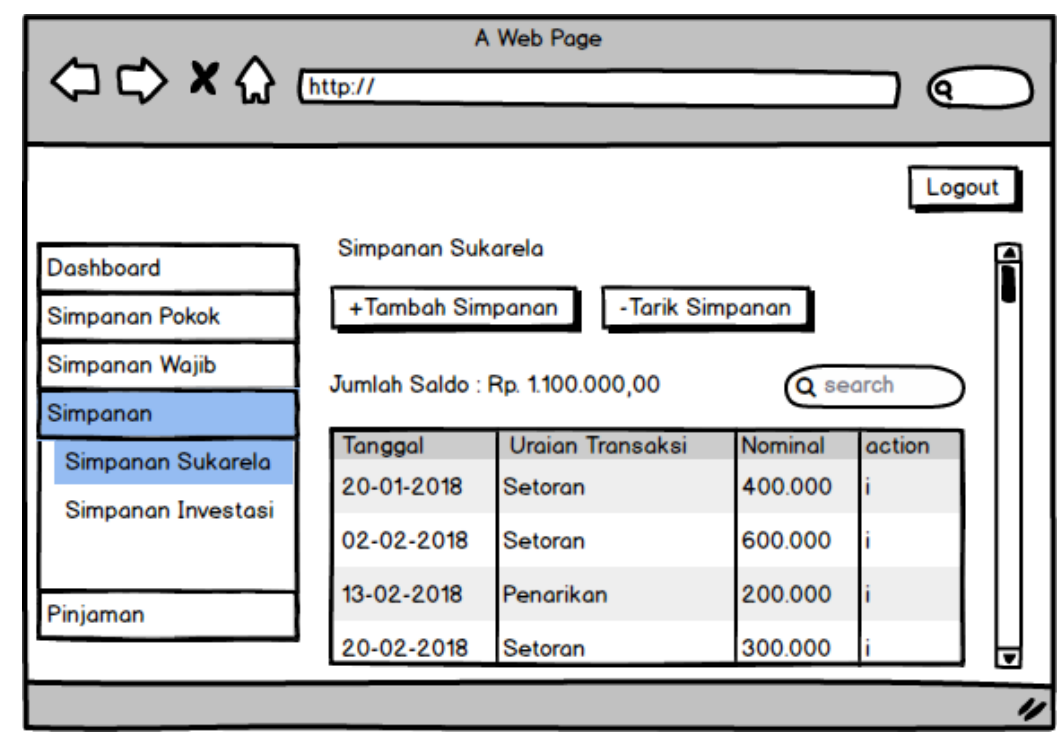

Gambar 4 design interface user anggota checking data simpanan sukarela

Design interface user anggota checking data simpanan sukarela menggambarkan ketika user anggota telah login maka user dapat memeriksa data transaksi dan saldo simpanan sukarela yang dimiliki user.

2. Design Interface User Checking Data Pinjaman 
Vol 7 No. 2 , 2019

(C2019 Ilmu Komputer Unila Publishing Network all rights reserved

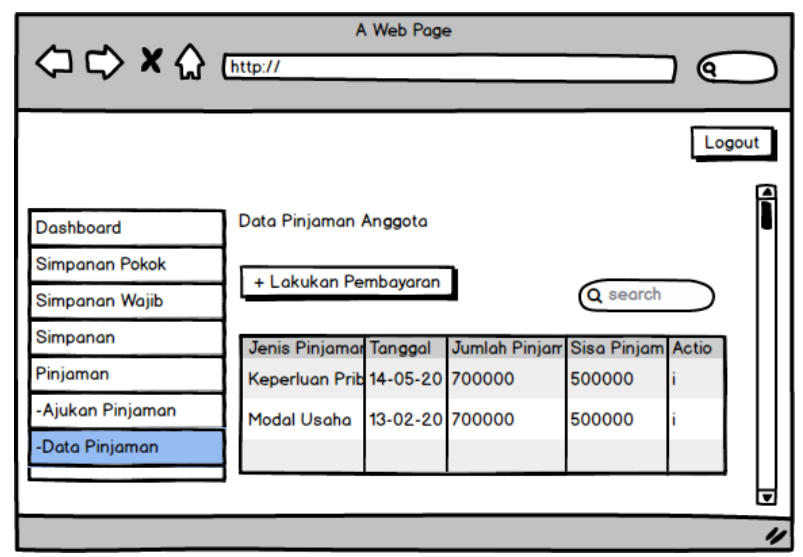

Gambar 5 design interface user checking data pinjaman

Design interface user checking data pinjaman menggambarkan ketika user anggota telah login maka user dapat memeriksa data pinjaman yang ditanggung oleh user.

\section{Tahap Pengkodean (Coding)}

Tahap ini dilakukan pembuatan sistem dengan menggunakan bahasa pemrograman PHP dan framework Laravel.

\section{Tahap Pengujian (Testing)}

Tahap ini dilakukan pengujian terhadap sistem mengenai kesesuaian fungsi-fungsi pada sistem dengan menggunakan metode Black Box Testing. Pengujian sistem dimaksudkan untuk menguji semua elemen-elemen perangkat lunak yang dibuat apakah sudah sesuai dengan yang diharapkan. Pendekatan kasus uji dalam penelitian ini adalah pengujian black box dengan metode Equivalence Partitioning (EP). Pengujian akan dilakukan dengan membagi domain masukan dari program ke dalam kelas-kelas sehingga test case dapat diperoleh. Pada pengujian ini harus diyakinkan bahwa masukan yang sama akan menghasilkan respon yang sama pula.

\section{PEMBAHASAN}

\subsection{Hasil}

Tahap selanjutnya yang dilakukan setelah tahap perencanaan dan perancangan yaitu tahap coding/pengkodingan. Pada proses pengkodingan, design interface yang telah dirancang dapat diimplementasikan dalam antarmuka (interface) sistem.

\subsubsection{Implementasi}

Tahap ini dilakukan implementasi dengan membuat kode program menggunakan Bahasa PHP dan framework Laravel. Hasil dari tahap kode program ditunjukkan dengan beberapa tampilan dengan penjelasan masing-masing fitur sebagai berikut :

a. Menampilkan data simpanan sukarela 


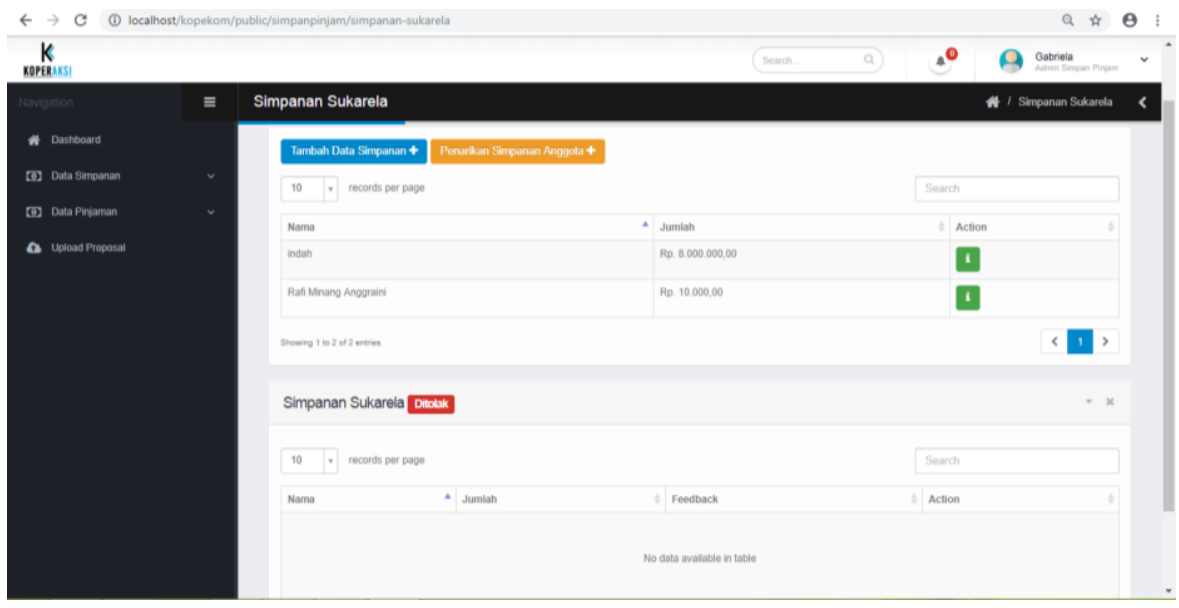

Gambar 6 tampilan data simpanan sukarela pada admin.

Pada Gambar 6 menunjukkan tampilan data simpanan sukarela. Admin dapat melihat data simpanan anggota, menambahkan transaksi simpanan serta melakukan penarikan simpanan.

b. Menampilkan data pinjaman

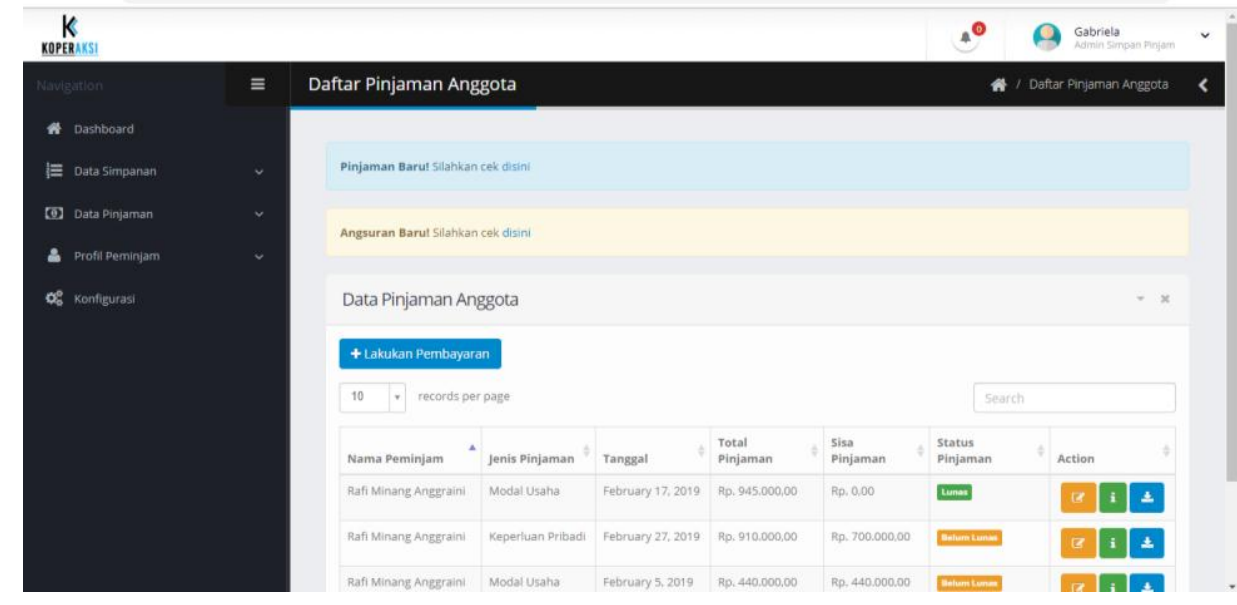

Gambar 7 tampilan data pinjaman pada admin.

Pada Gambar 7 menunjukkan tampilan data pinjaman . Admin dapat melihat data pinjaman anggota, memverifikasi pinjaman dan angsuran baru dan menginputkan data pembayaran pinjaman.

\subsubsection{Pengujian Program}

Pengujian Sistem Informasi Simpan Pinjam Multikoperasi menggunakan teknik black box testing. Black box testing merupakan suatu teknik pengujian perangkat lunak yang berfokus pada persyaratan fungsional. Black box testing memungkinkan pengembang mendapatkan serangkaian kondisi input yang sepenuhnya menggunakan persyaratan fungsional untuk suatu program [9]. Untuk metode black box testing yang digunakan adalah equivalent partitioning (EP). EP merupakan metode black box testing yang membagi domain masukan dari program kedalam kelas-kelas sehingga terbentuk sebuah test case [10]. Pengujian pada penelitian ini dilakukan dengan membagi kelas uji berdasarkan aktor dalam SI Simpan Pinjam Multikoperasi. Pengujian dilakukan dengan beberapa kasus uji dengan hasil pengujian telah sesuai (valid) serta beberapa catatan. Beberapa catatan hasil pengujian yang telah dilakukan oleh 
pihak koperasi, penguji menyarankan untuk biaya admin yang ada pada pinjaman pribadi menjadi pemasukan bagi koperasi dan tidak dihitung menjadi satu pada pinjaman serta diberi keterangan sifat pinjaman seperti pembeda pinjaman syariah atau pinjaman konvensional.

\section{SIMPULAN}

Dari hasil penelitian yang dilakukan, dapat diambil simpulan sebagai berikut.

1. Telah dibangun Sistem Informasi Simpan Pinjam Multikoperasi menggunakan Framework Laravel 5.5 untuk membantu mengelola data anggota dan nonanggota koperasi simpan pinjam

2. SI Simpan Pinjam Multikoperasi telah berhasil memberikan informasi mengenai data simpanan, pinjaman serta investasi

3. SI Simpan Pinjam Multikoperasi telah berhasil memberikan informasi megenai banyaknya angsuran yang telah dibayar serta memberikan keterangan berapa sisa pinjaman yang harus dibayar oleh peminjam.

4. SI Simpan Pinjam Multikoperasi dapat digunakan oleh lebih dari satu koperasi.

\section{DAFTAR PUSTAKA}

[1] W. N. d. Sunindhia, Koperasi dan Perekonomian Indonesia, Jakarta: Rineka Cipta, 2009.

[2] U. Teman, "Uang Teman," 29 Oktober 2015. [Online]. Available: UangTeman. https://uangteman.com/blog/berita-bisnis/koperasi-simpan-pinjam/ . [Diakses 20 November 2018].

[3] Baswir. R, Agenda Ekonomi Kerakyatan, Yogyakarta: Pustaka Pelajar, 1997.

[4] D. C. Wyld, "The Utility Of Cloud Computing As A New Pricing And Consumption Model For Information Technology," International Journal of Database Management Systems (IJDMS), pp. 1-20, 2009.

[5] S. Yao PKF. and Sezer, "Software as a Service-Understanding Security Issues," Science and Information Conference, 2015.

[6] G. A. Kulkarni, M. Mitra, and J. Gambhir, "Cloud Computing-Software as Service," vol. 2, pp. 2-6, 2011.

[7] A. Budiyanto, Pengantar Cloud Computing, 2012.

[8] M. P. B. Rajegore and M. S. G, "Issues \& Solution of SAAS Model in Cloud Computing," pp. 40-44, 2014.

[9] R. S. Pressman, Rekayasa Perangkat Lunak, Yogyakarta: AndiOffset, 2012.

[10] P. Busono, Testing \& Implementasi, Jakarta: Pusat Pengembangan Bahan Ajar UMB, 2009. 